\title{
BENTUK MUSIK DAN FUNGSI KESENIAN JAMJANENG GRUP "SEKAR ARUM" DI DESA PANJER KABUPATEN KEBUMEN
}

\author{
Ali Fatkhurrohman \\ Jurusan Sendratasik, FBS, Universitas Negeri Semarang, Indonesia
}

S. Suharto $\bowtie$

Jurusan Sendratasik, Fakultas Bahasa dan Seni, Universitas Negeri Semarang, Indonesia

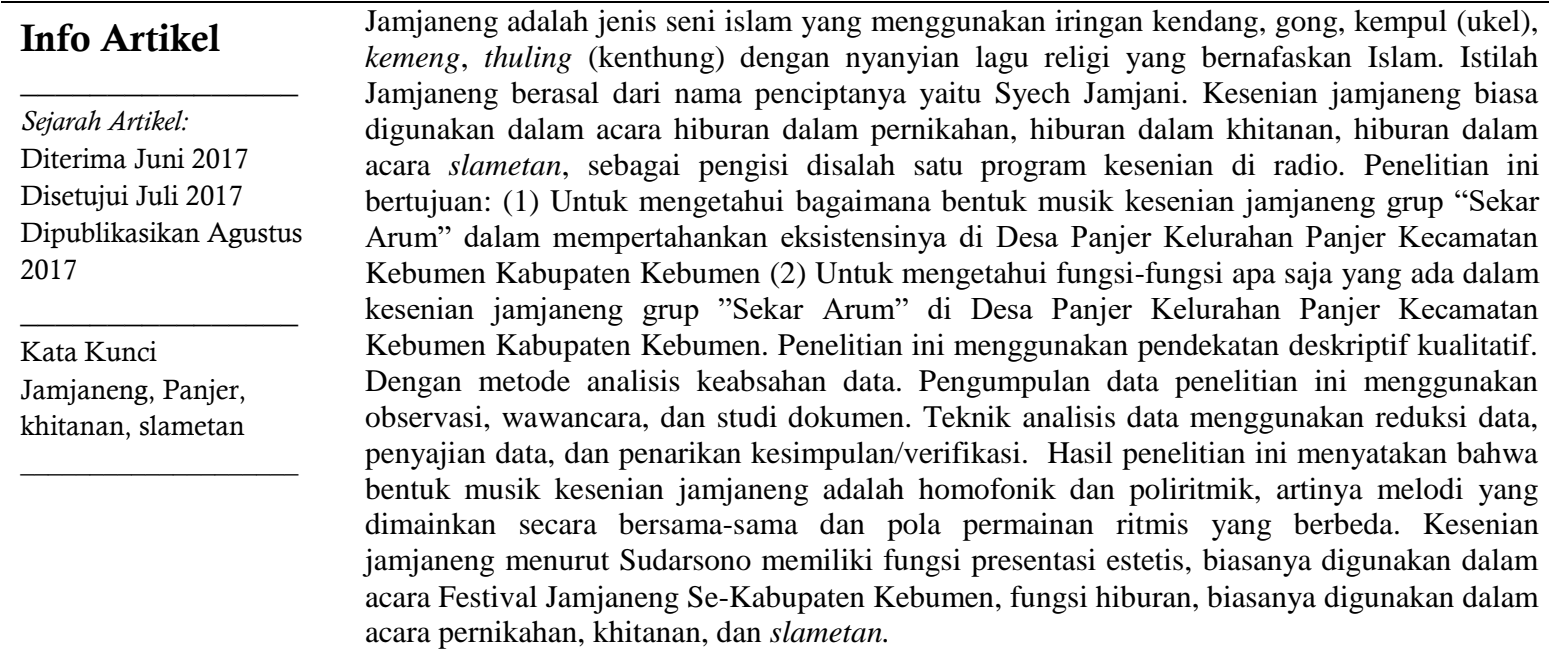

\footnotetext{
Jurusan Sendratasik, Kampus Sekaran Unnes

Gunungpati, Semarang 50229

Email: Suharto@mail.unnes.ac.id
}

\section{PENDAHULUAN}

Seni dalam kehadirannya di dunia ini selalu dibutuhkan oleh manusia dimanapun mereka berada dan kapan saja, maka secara sederhana dapat dikatakan bahwa perkembangan seni selalu seiring dengan perkembangan masyarakat pendukungnya. Pada masyarakat primitif, seni hampir segala-galanya. Ketika sebuah masyarakat mengalami perubahan kehidupan tata politiknya menjadi negara yang merdeka dan demokratis, akan lahir pula seni yang sangat menonjolkan kebebasan serta mementingkan individu Pada era inilah kita selalu mendengar bahwa lukisan ini adalah karya pelukis ini; musik itu adalah karya komponis itu; dan tari yang begitu adalah karya koreografer itu. Penciptaan sebuah karya seni selalu memiliki tujuan. Secara garis besar tujuan itu bisa dikelompokan menjadi tiga, yaitu : (1) seni untuk tujuan ritual; (2) seni untuk tujuan presentasi estetis; dan (3) seni sebagai hiburan pribadi (Soedarsono, $1999: 1$ - 2).

Kebumen adalah salah satu kabupaten yang ada di provinsi Jawa Tengah, yang didalamnya mempunyai potensi-potensi yang beragam dan mempesona. Letak geografis Kota Kebumen adalah berbatasan timur dengan Kabupaten Purworejo dan Kabupaten Wonosobo, barat dengan Kabupaten Banyumas 
dan Kabupaten Cilacap, utara dengan Kabupaten Banjarnegara, dan selatan dengan Samudera Indonesia.

Menurut Soedarsono jika
diklarifikasikan kesenian di Kebumen menjadi sebagai berikut : (1) seni untuk tujuan ritual: gebyak cah angon, ingkungan suran, kirab pusaka; (2) seni untuk tujuan presentasi estetis: tari lawet, wayang kulit, lengger, jamjaneng; (3) seni sebagai hiburan pribadi: rebana, campursari, ebleg, jamjaneng.

Dari berbagai kesenian yang berkembang di Kebumen kesenian jamjaneng dipilih oleh penulis untuk dijadikan objek penelitian karena kesenian ini adalah kesenian asli Kebumen yang sudah lama ada dan masih tetap eksis sampai sekarang. Jamjaneng merupakan salah satu contoh dari sekian banyaknya musik tradisional yang ada di Indonesia. Musik tradisional jamjaneng adalah jenis seni islam yang menggunakan iringan kendang, gong, kempul (ukel), kemeng, thuling (kenthung) dengan nyanyian lagu religi yang bernafaskan Islam. Kesenian jamjaneng adalah kesenian yang hidup ditengah masyarakat, disamping kesenian yang lainnya, seperti Kuda Lumping, Rebana, Kenthongan, dan Tanjidor. Istilah Jamjaneng berasal dari nama penciptanya yaitu Syech Jamjani. Pemain jamjaneng berusia 40-70 tahun.

$$
\text { Kesenian Jamjaneng lahir dan }
$$
berkembang di Desa Panjer. Desa Panjer adalah desa yang ada di Kebumen yang masih mengembangkan kesenian jamjaneng. Jarak tempuh desa Panjer tidak jauh dari pusat kota Kebumen. Masyarakat desa tersebut kebanyakan bermata pencaharian sebagai wirausaha dan pedagang. Desa Panjer termasuk dalam masyarakat modern, tetapi mereka tetap mau melestarikan kesenian tradisional yang sudah menjadi warisan leluhur. Mayoritas penduduk Desa Panjer adalah beragama Islam maka dari itu kesenian jamjaneng sangat mungkin sekali lahir di Desa Panjer.

Penikmat musik jamjaneng yang ada di Kebumen kebanyakan adalah kalangan masyarakat yang berusia lanjut. Hal ini dikarenakan generasi muda sekarang kurang tertarik dengan kesenian tradisional jamjaneng sebab generasi muda sekarang banyak menyukai musik-musik modern.

Seperti yang telah disampaikan Soedarsono, jamjaneng termasuk dalam kategori kesenian yang bertujuan sebagai presentasi estetis dan hiburan pribadi. Kesenian jamjaneng selain bisa dijadikan sebagai media hiburan dalam hal seni, jamjaneng dalam agama islam yaitu bertujuan untuk mendekatkan diri kepada Tuhan dengan doa dan sholawat Nabi yang dilantukan disetiap syair lagunya. Selain itu lagu-lagu yang dinyanyikan ada juga yang menceritakan kesenian jamjaneng itu sendiri. Perkembangan kesenian Jamjaneng di Desa Panjer ikut dimotori oleh grup "Sekar Arum".

Berdasarkan latar belakang diatas penulis tertarik untuk mengetahui bagaimana bentuk musik dan fungsi kesenian Jamjaneng dalam mempertahankan eksistensinya terutama pada grup "Sekar Arum" di Desa Panjer Kelurahan Panjer Kecamatan Kebumen Kabupaten Kebumen.

Berdasarkan paparan latar belakang di atas, maka masalah peneliti adalah untuk mengetahui (1) Bagaimana bentuk musik kesenian jamjaneng dalam grup "Sekar Arum" di Desa Panjer Kelurahan Panjer Kecamatan Kebumen Kabupaten Kebumen ? (2) Apakah fungsi kesenian jamjaneng di Desa Panjer Kelurahan Panjer Kecamatan Kebumen Kabupaten Kebumen $?$ 
Penelitian yang peneliti lakukan senada dengan penelitian yang telah dilakukan oleh Hendriyanto (2011) dengan judul "Musik Tradisional Jamjaneng Awak Tugu Manunggal di Desa Kutowinangun Kecamatan Kutowinangun Kabupaten Kebumen: Kajian Pola Permainan Musiknya", Hendriyanto membahas bagaimanakah arransemen musik tradisional Jamjaneng Awak Tugu Manunggal di Desa Kutowinangun Kecamatan Kutowinangun Kabupaten Kebumen. Sedangkan pembahasan tentang pemaknaan eksistensi telah disampaikan secara jelas oleh Utari (2011) dalam penelitiannya berjudul "Eksistensi Pembelajaran Tari Jawa Pada Siswa Etnis Tionghoa di SMP Karangturi Semarang". Penelitian selanjutnya yang digunakan sebagai acuan dalam penelitian terdahulu oleh peneliti yaitu Junaidi (2013) yang berjudul "Janengan Sebagai Seni Tradisional Islam-Jawa", jurnal ini membahas tentang Janengan sebagai seni tradisional Islam-Jawa. Penelitian selanjutnya oleh Cahyadi (2015) dalam skripsinya berjudul "Fungsi dan Bentuk Penyajian Kesenian Jamjaneng di Dusun Pedurenan Desa Krakal Alian Kebumen" membahas bagaimana fungsi dan bentuk kesenian tradisional Jamjaneng. Selanjutnya penelitian mengenai eksistensi juga dilakukan oleh Maharani (2016) dalam skripsi yang berjudul "Eksistensi Kesenian Kenthongan Grup Titir Budaya di Desa Karangduren, Kecamatan Bobotsari, Kabupaten Purbalingga” yang membahas mengenai eksistensi kesenian kenthongan Grup Titir Budaya.

\section{METODE}

Penelitian ini bersifat deskriptif kualitatif, yang menggambarkan atau menguraikan permasalahan yang berhubungan dengan keadaan atau status fenomena kelompok tertentu dalam bentuk kata - kata, gambar, dan bukan angka angka (Moleong, 1989: 11). Penelitian kualitatif sering disebut juga Thick Description (deskripsi tebal).

Adapun teknik penelitian dari penelitian ini yaitu: (1) Observasi, menurut Nasution (Sugiyono, 2011: 226) Observasi adalah dasar semua ilmu pengetahuan. Para ilmuwan hanya dapat bekerja berdasarkan data, yaitu fakta mengenai dunia kenyataan yang diperoleh melalui observasi. Aspek yang di observasi meliputi lokasi dan setting penelitian, sarana dan prasarana yang meliputi tempat dan alat musik yang digunakan di grup "Sekar Arum", dan bentuk musik pada grup "Sekar Arum". (2) Wawancara adalah percakapan dengan maksud tertentu. Percakapan dilakukan dua belah pihak yaitu pewawancara (interviewees) yang mengajukan pertanyaan dan pihak yang diwawancarai (interviewee) yang memberikan jawaban atas pertanyaan tersebut (Moleong, 2000: 15). Dalam penelitian ini agar data yang didapatkan valid peneliti mewancarai pendiri serta pimpinan grup jamjaneng "Sekar Arum", koordinator grup jamjaneng "Sekar Arum", dan masyarakat Desa Panjer dan penikmat seni jamjaneng. Aspek-aspek yang diamati oleh peneliti yaitu lokasi penelitian, sejarah terbentuknya grup "Sekar Arum", struktur organisasi serta sarana dan prasarana pada grup "Sekar Arum", bentuk musik dan fungsi grup "Sekar Arum", dan manajemen pengelolaan pada grup "Sekar Arum". (3) Studi Dokumen, dokumentasi adalah mencari data yang berasal yang berasal dari catatan, buku, surat kabar, majalah, notulen, dan agenda yang berhubungan dengan objek yang diteliti (Arikunto, 1983: 188). Agar data yang didapatkan valid penulis melampirkan dokumentasi seperti gambaran 
umum lokasi penelitian, dokumentasi pada saat pertunjukan, dokumentasi pada saat wawancara.

Dalam penelitian ini untuk menguji keabsahan data peneliti menggunakan triangulasi. Triangulasi adalah pengecekan data dari berbagai sumber dengan berbagai sumber dengan berbagai cara, dan berbagai waktu. Ada tiga teknik pemeriksaan data dalam triangulasi data yaitu sumber, metode, dan teori. Teknik yang digunakan dalam penelitian ini ialah sumber dan metode. (1) Sumber, untuk mengecek kembali data yang diperoleh dengan informasi dokumen serta sumber informasi untuk mendapat derajad kepercayaan adanya informasi dan kesamaan pandang serta pemikiran. Dalam penelitian ini, penulis menggali fakta dari informan, kondisi masyarakat Desa Panjer, serta fungsi kesenian jamjaneng bagi personil dan masyarakat Desa Panjer. (2) Metode, metode digunakan untuk mendapatkan keabsahan dalam penulisan hasil penelitian. Dalam perolehan data, peneliti mendapatkan dari berbagai informasi sehingga perlu adanya pengabsahan data untuk mempertanggung jawabkan kebenarannya. Dalam penelitian ini, peneliti menggunakan wawancara mendalam terhadap narasumber, serta mendokumentasikan kegiatan grup jamjaneng "Sekar Arum".

Teknik analisis data yang digunakan dalam penelitian ini adalah reduksi data, penyajian data, dan penarikan kesimpulan/verifikasi. Reduksi data merupakan kegiatan merangkum data, memilih hal-hal yang pokok, memfokuskan pada hal-hal penting, dicari tema dan polanya (Sugiyono, 2011:247). Dalam penelitian ini, reduksi data digunakan untuk memfokuskan data yang diperoleh di lapangan diantaranya dokumen notasi dan syair lagu, rekaman audio visual, dokumen berupa foto, serta data-data grup jamjaneng "Sekar Arum". Dalam penelitian kualitatif, penyajian data bisa dilakukan dalam bentuk uraian singkat, bagan, hubungan antar kategori, flowchart dan sejenisnya. Data yang diperoleh antara lain gambaran umum Desa Panjer, struktur organisasi dan kondisi personil grup "Sekar Arum", bentuk musik yang meliputi lagu yang di bawakan, analisis lagu dan pola yang dimainkan, dan alat musik serta cara memainkannya. Kesimpulan dalam penelitian kualitatif adalah merupakan temuan baru yang sebelumnya belum pernah ada. Data yang akan diverifikasi pada penelitian ini terkait dengan bentuk musik dan fungsi kesenian jamjaneng grup "Sekar Arum" diantaranya: analisis lagu jamjaneng serta lagu-lagu yang dibawakan, alat musik yang digunakan, pola permainan alat musiknya, serta fungsi apa saja yang ada dalam kesenian jamjaneng grup "Sekar Arum".

\section{HASIL PENELITIAN DAN PEMBAHASAN}

\section{Bentuk Musik Kesenian Jamjaneng Grup "Sekar Arum"}

Menurut Jamalus (dalam Hendriyanto, 2011: 11) melodi ialah susunan rangkaian (bunyi dengan getaran teratur) yang terdengar berurutan serta berirama, dan mengungkapkan suatu gagasan. Melodi yang digunakan dianalisa bagaimana gerak intervalnya, menggunakan tangga nada apa, apakah ada bentuk melodi berulang - ulang secara tetap, dan lain sebagainya. Berikut adalah hasil analisis bentuk lagu Digdoyo Endi : 




Gambar 1. Notasi Analisis Bentuk Lagu Digdoyo Endi

Analisis melodi lagu digdoyo endi lagu Digdoyo Endi adalah lagu 1 bagian dengan 1 kalimat tanya $\left(A, A^{1}, A^{2}\right)$ dan 2 kalimat jawab $\left(X, X^{1}, X^{2}, Y\right.$, $Y^{2}$ ). Lagu Digdoyo Endi menggunakan tangga nada minor dan memiliki jarak interval yang cukup bervariatif dari jarak tonika sampai dominan. Lagu Digdoyo Endi memiliki sifat repetisi karena dalam satu kali sajian terdapat dua kali pengulangan dengan melodi yang sama.

Menurut Jamalus (dalam Hendriyanto, 2011: 10) ritme adalah suatu urutan rangkaian gerak yang terbentuk dari sekelompok bunyi dan diam dengan bermacam - macam lama waktu atau panjang pendeknya, membentuk pola irama bergerak menurut pulsa dalam ayunan birama. Ritme dianalisa dengan jelas, baik alur, ketukan, dan tanda biramanya, atau mungkin juga menggunakan tanda irama yang lain. Ritme utama yang menonjol dikendalikan oleh alat musik, dan pola ritme ditulis dengan not balok. Berikut adalah hasil analisis ritme alat musik jamjaneng Grup "Sekar Arum" :

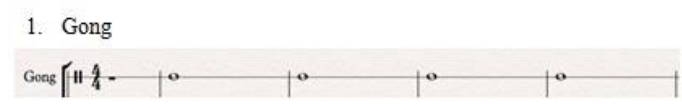

Notasi 1. Pola Permainan Alat Musik Gong

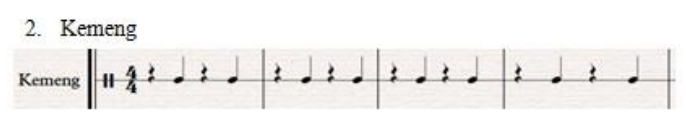

Notasi 2. Pola Permainan Alat Musik Kemeng 3. Kempul

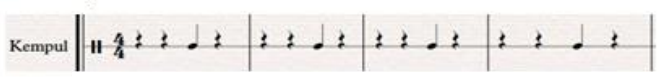

Notasi 3. Pola Permainan Alat Musik Kempul

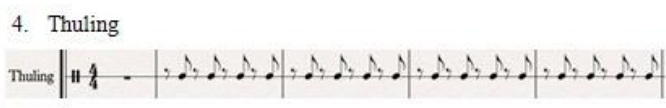

Notasi 4. Pola Permainan Alat Musik Thuling

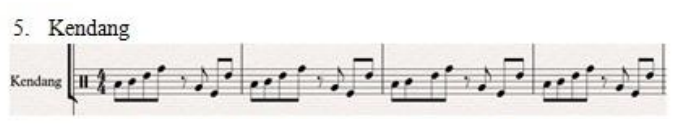

Notasi 5. Pola Permainan Alat Musik Kendang

Analisis pola ritme permainan kesenian jamjaneng Pola ritme dalam kesenian jamjaneng dimainkan oleh seluruh alat musik. Alat musik dalam kesenian jamjaneng adalah gong, kemeng, kempul, thuling, kendang jawa. Gong dalam kesenian jamjaneng digunakan sebagai ketukan kuat sekaligus menjadi patokan bagi pemain alat 
musik yang lain. Kemeng, kempul, dan thuling berfungsi sebagai filler atau imbal. Kendang adalah alat musik yang digunakan sebagai pemimpin dalam sebuah pertunjukan. Alat musik kendang dimainkan dengan bebas tanpa pola tertentu bergantung dari pemain ataupun lagu yang dimainkan

Menurut Pamuji (dalam Hendriyanto, 2011: 12) mengartikan bahwa harmoni sebagai gabungan dari beberapa nada yang dibunyikan serempak atau arpeggio (berurutan) atau tinggi rendah nada tersebut tidak sama tetapi selaras terdengar dan merupakan kesatuan yang bulat. Harmoni meliputi keselarasan, alur melodi, apakah ada pembagian suara, perpaduan alat musiknya bagaimana, dan lain sebagainya.

Berikut adalah bentuk harmonisasi pada pola permainan Grup Jamjaneng "Sekar Arum adalah sebagai berikut :

\section{Digdoyo Endi}

Full Score
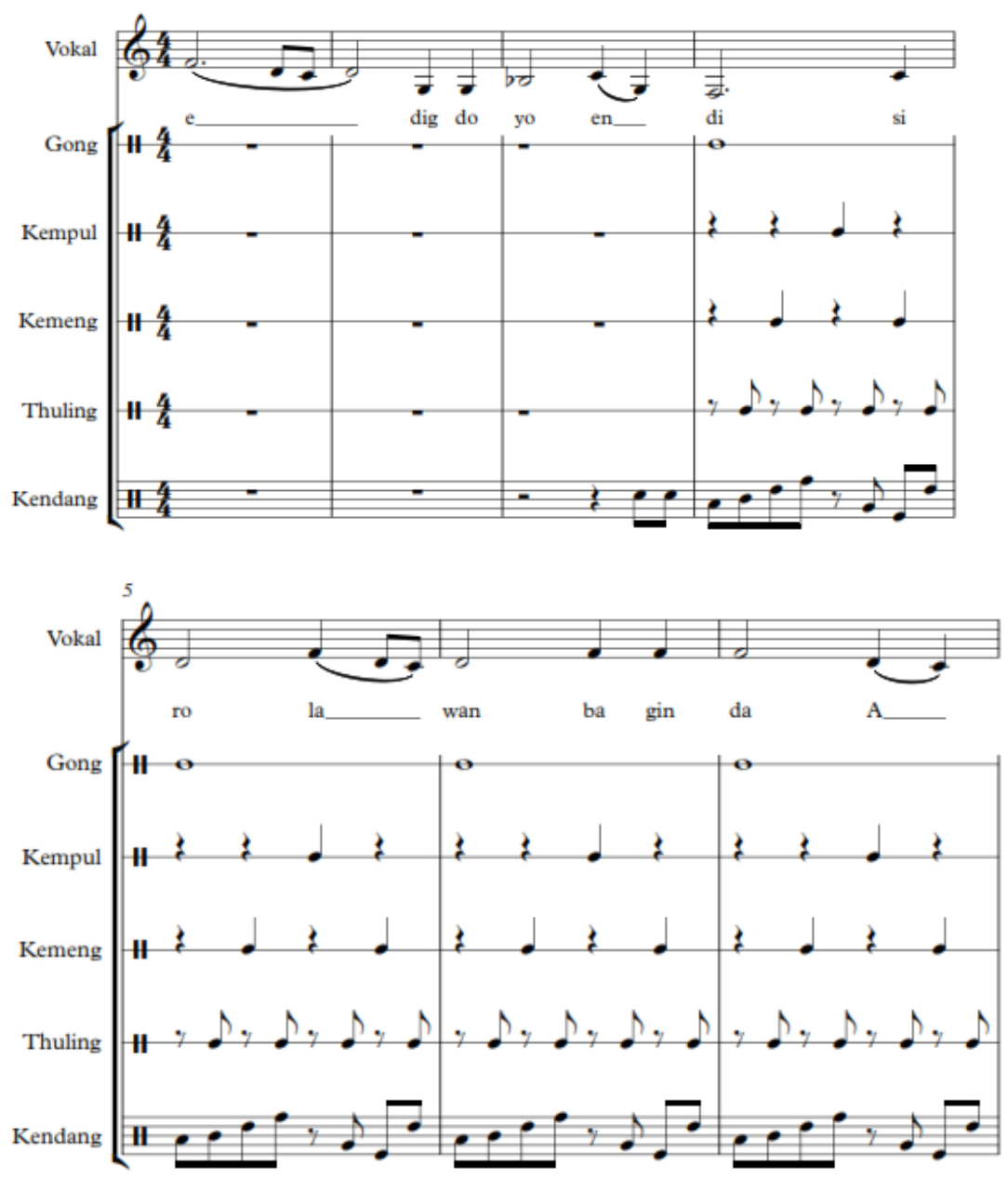

Gambar 2. Notasi Analisis Harmoni Lagu Digdoyo Endi

Analisis Harmoni permainan kesenian jamjaneng

Harmonisasi dalam kesenian jamjaneng bukan harmonisasi melodi melainkan harmonisasi ritmis atau bisa disebut poliritmik hal ini dikarenakan 
semua alat musik yang digunakan dalam kesenian jamjaneng adalah alat musik ritmis. Sedangkan melodinya dimainkan secara unisono karena melodi pada kesenian jamjaneng hanya ada pada vokal dan dinyanyikan bersama-sama atau secara bergantian dalam satu suara. Poliritmik adalah tekstur musik yang ritme dan melodinya berbeda yang disajikan dalam satu waktu yang bersamaan, tetapi tetap berdasar kepada prinsip-prinsip harmoni.

Menurut Joseph (dalam Hendriyanto, 2011: 13) timbre adalah ciri khas bunyi yang terdengar bermacam-macam, yang dihasilkan oleh bahan sumber bunyi yang berbeda-beda, dan cara memproduksi nada yang bermacam-macam.

Alat yang digunakan dalam kesenian jamjaneng Grup "Sekar Arum” adalah gong, kemeng, kempul, thuling, kendang jawa, semuanya adalah alat musik perkusi. Gong dalam kesenian ini memiliki merupakan alat musik yang mempunyai diameter paling besar dari yang lainnya dan membrannya terbuat dari kulit sapi. Warna suara dan bentuknya mirip seperti gong dalam alat musik rebana, hanya saja gong dalam kesenian jamjaneng berjumlah satu buah

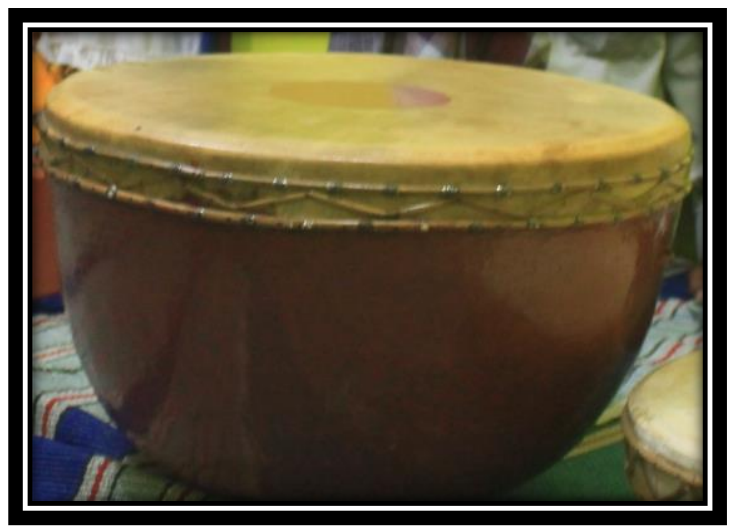

Gambar 2. Alat Musik Gong
. Cara memainkannya yaitu dengan cara memiringkan gong dipegang dengan tangan kiri fungsinya agar suara bass dari gong keluar dan dimainkan dengan telapak tangan kanan dengan memukul bagian pinggir dari membran, dan dimainkan selalu pada ketukan pertama.

Kemeng dan kempul dalam kesenian ini bentuknya hampir sama dengan gong, bedanya kemeng lebih kecil diameternya daripada gong sedangkan kempul diameternya lebih kecil dari pada kemeng. Cara memainkannya yaitu dengan telapak tangan dan dipukul bagian pinggir dari membran. Thuling dari dua buah bambu utuh yang dibentuk dengan panjang sekitar $30 \mathrm{~cm}$. Alat musik ini dimainkan dengan cara dipukul dengan menggunakan pemukulnya yang terbuat dari kayu, thuling selalu dimainkan pada ketukan up.

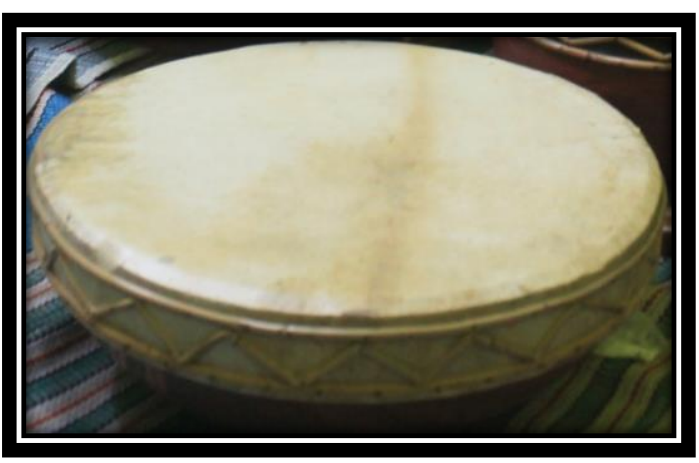

Gambar 3. Alat Musik Kemeng

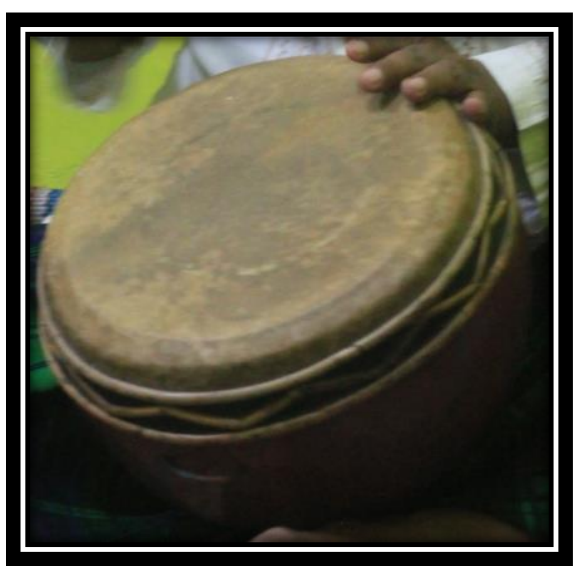

Gambar 4. Alat Musik Kempul 


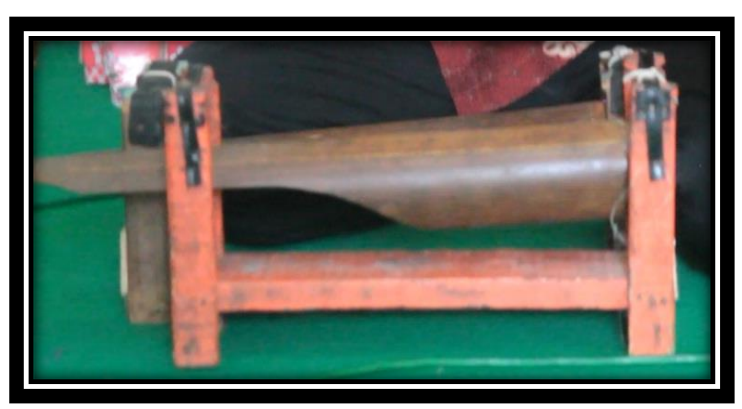

Gambar 5. Alat Musik Thuling

Kendhang dalam kesenian jamjaneng adalah satu-satunya alat musik yang melakukan improvisasi pola permainan. Menurut Sutarno, kendhang berbentuk tabung dengan sisi yang satu besar untuk menghasilkan bunyi "dhang" sedangkan sisi yang lain mengecil untuk menghasilkan bunyi "tak" dan "thung". Kendhang terbuat dari kayu dengan membran kulit sapi dan dimainkan dengan cara dipukul menggunakan telapak tangan (hasil wawancara Kamis, 27 April 2017, telah diijinkan untuk dikutip).

\section{Fungsi Kesenian Jamjaneng pada Grup} "Sekar Arum" Desa Panjer Kelurahan Panjer

\section{Kecamatan Kebumen Kabupaten Kebumen}

Fungsi seni dalam masyarakat tradisional dalam pemahaman umum sering diartikan hanya untuk hiburan. Lebih kompleks dapat dijelaskan bahwa seni merupakan sarana legitimasi, ketika seni itu berada di dalam istana (keraton). Kesenian memiliki beberapa fungsi yaitu : (1) seni untuk tujuan ritual (2) seni untuk tujuan presentasi estetis (3) seni sebagai hiburan pribadi (Soedarsono, 1999 : 1-2).

Kesenian jamjaneng dalam fungsi presentasi estetis biasanya dimainkan dalam acara Festival Jamjaneng Se-Kabupaten Kebumen dan Lapanan Paguyuban Seni Tradisional Jamjaneng
Kabupaten Kebumen. Agar Grup "Sekar Arum" tetap terlihat kompak dalam acara-acara tersebut selalu mengenakan kostum yang seragam, hal ini dikarenakan agar menarik perhatian penonton. Lagu-lagu yang dibawakan Grup "Sekar Arum" dalam fungsi estetis adalah Assalam, Allohumasol, Annabi, Dzikrulloh, Yo Elingo, Bagus Endi, Sugih Endi, Digdoyo Endi, Ayu Endi, Sucekno, Allohuma, Jaman Akhir.

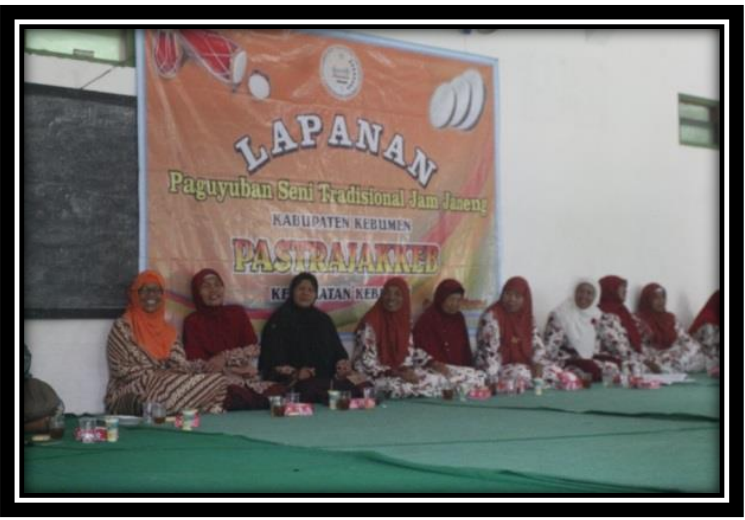

Gambar 6. Dokumentasi pada acara Lapanan Paguyuban Seni Tradisional Jamjaneng Kecamatan Kebumen

Kesenian jamjaneng dalam fungsi untuk hiburan dimainkan dalam acara hiburan dalam pernikahan, hiburan dalam khitanan, hiburan dalam acara slametan, sebagai pengisi disalah satu program kesenian di radio. Pada fungsi hiburan terkadang ada permintaan lagu atau request lagu dari penonton ataupun dari yang empunya rumah. Permintaan lagunya bermacam-macam seperti lagu sholawat ataupun lagu campursari yang sudah diganti lirknya menjadi lagu sholawat, diantaranya adalah Pengantin Baru, Jilbab Putih, Globalisasi dan lain sebagainya. Kostum yang digunakan dalam fungsi ini yaitu terkadang berseragam dan terkadang memakai pakaian muslim bergantung pada acara hiburannya. 


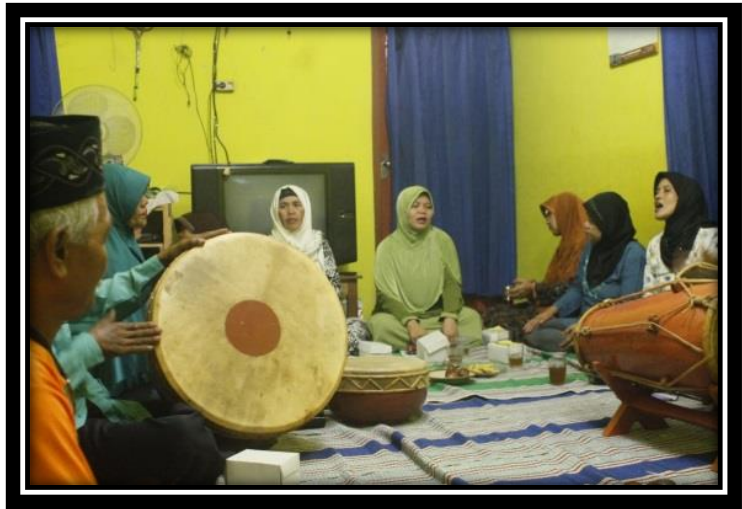

Gambar 7. Dokumentasi pada Acara Slametan

Fungsi seni sebagai tujuan ritual berlangsung pada masa peradaban manusia primitif. Kehidupan seni waktu itu belum mengenal adanya alat musik, busana, gerak, tata panggung dan lainnya. Kecenderungan seni ritual pada masa lalu menekan kan pada tujuan fisik atau bentuk sehingga pada fungsi ini seni pertunjukan memiliki bentuk musik yang sangat sederhana. Kesenian jamjaneng tidak diperuntukan pada fungsi ini.

\section{Fungsi Musik Kesenian Jamjaneng pada Grup "Sekar Arum" Desa Panjer Kelurahan Panjer}

\section{Kecamatan Kebumen Kabupaten Kebumen}

Dalam perumusan fungsi musik menurut Alan P. Merriam, kesenian jamjaneng dapat diklasifikasikan sebagai berikut: (1) fungsi pengungkapan emosional, pada awal kemunculan kesenian jamjaneng, kesenian jamjaneng digunakan sebagai media pengungkapan emosional karena warga masyarakat Desa Panjer yang notabennya sebagai pensiunan dan ibu rumah tangga, menggunakan waktu luangnya untuk menyalurkan ekspresi. Penyaluran ekspresi ini merupakan bagian dari fungsi pengungkapan emosional. (2) fungsi penghayatan estetis, jamjaneng di Desa Panjer khususnya Grup "Sekar
Arum" sangat dinanti-nanti penampilannya, penikmat seni Jamjaneng ataupun penonton bisa menikmati keindahan musik Jamjaneng yang dimainkan secara poliritmik hingga membentuk pola ritmis yang harmonis dan lirik lagu yang mengandung banyak makna untuk kehidupan manusia yang dinyanyikan secara unisono. (3) fungsi hiburan, Desa Panjer mempunyai berbagai macam kesenian diantaranya Tari Lawet, Solo Organ, Calung, dan Rebana. Diantara keseniankesenian tersebut, kesenian Jamjaneng juga sangat ditunggu-tunggu oleh masyarakat Desa Panjer untuk keperluan hiburan. (4) fungsi komunikasi, Jamjaneng di Desa Panjer dijadikan sebagai ajang untuk silaturahmi bagi setiap pelakunya, untuk penikmat, penonton, dan pemainnya. Hal ini menjadikan Desa Panjer menjadi desa yang rukun karena terjalin komunikasi yang baik antar warga. (5) fungsi perlambangan, musik Jamjaneng juga bisa dikatakan untuk fungsi perlambangan, dalam tempo yang pelan musik jamjaneng menceritakan tentang syair lagu yang mengandung puji-pujian terhadap Tuhan ataupun tentang ajaran Nabi untuk para umatnya. Musik Jamjaneng yang agak cepat temponya digunakan untuk lagu-lagu dangdut atau sholawat yang diubah liriknya dan diaransemen ulang ke dalam bentuk arnsemen lagu Jamjaneng. (6) fungsi reaksi jasmani, jamjaneng merupakan musik yang sangat bisa dinikmati di Desa Panjer. Setiap pertunjukan jamjaneng, musik jamjaneng mampu membuat penontonnya menari. Jika musik dengan tempo pelan penonton menari dengan lemah gemulai, jika musiknya dengan tempo yang cepat maka penonton pun ikut menari dengan gerakan yang cepat mengikuti alunan musiknya. (7) fungsi yang berkaitan dengan norma sosial, jamjaneng memiliki fungsi sesuai dengan liriknya, yaitu 
mengandung banyak petuah dan norma-norma yang berlaku di kehidupan masyarakat, yaitu tentang bagaimana ajaran Nabi-nabi kepada umatnya pada jaman dahulu. (8) fungsi pengesahan lembaga sosial, pada jaman dahulu penyebaran agama Islam di Kebumen khususnya juga dipelopori oleh kesenian Jamjaneng. Oleh penciptanya yaitu Syech Jamjani, kesenian Jamjaneng juga digunakan untuk penyebaran agama Islam melalui musik. (9) fungsi kesinambungan budaya, fungsi ini hampir sama dengan fungsi norma sosial yaitu melanjutkan budaya sebelumnya. Tujuan dari kesenian Jamjaneng yaitu untuk mengajarkan atau menjadi wejangan bagi umat Islam untuk menjalankan perintah-Nya dan mejauhi larangan-Nya yang sudah diajarkan oleh para Nabi melalui musik. (10) fungsi pengintegrasian masyarakat, kesenian Jamjaneng menjadi kesenian yang sangat akrab di kalangan masyarakat Desa Panjer. Kesenian Jamjaneng tanpa disadari menjadikan antar personil/pemain Grup "Sekar Arum” menjadi lebih erat kekeluargaannya. Pada saat bermain musik, personil saling kompak dan saling mengisi satu sama lain hingga terbentuklah musik yang indah yang bisa dinikmati oleh Masyarakat Desa Panjer. Para penikmat musik Jamjaneng di Desa Panjer juga merasakan dampak yang demikian, bisa saling berkumpul dengan tetangga dan sekitarnya sehingga menjadikan masyarakat Desa Panjer yang harmonis.

\section{SIMPULAN DAN SARAN}

Alat musik jamjaneng pada grup "Sekar Arum" terdiri dari dari lima alat musik membranophone yaitu gong, kemeng, kempul, thuling, dan kendhang, yang dimainkan secara poliritmik sedangkan melodinya hanya terdapat pada vokal yang dimainkan secara homofonik.
Alat musik gong digunakan sebagai ketukan kuat dengan memainkan not penuh pada setiap birama, kemeng digunakan sebagai pengisi, dimainkan pada ketukan ke 2 dan ke 4 pada setiap birama dengan nilai not seperempat, kempul digunakan sebagai pengisi dimainkan pada ketukan ke 3 dalam setiap birama dengan nilai not seperempat, thuling digunakan juga sebagai pengisi dimainkan pada ketukan up atau sinkup dalam setiap birama dengan nilai not seperenambelasan, kendhang berfungsi untuk memimpin alat musik yang lain. Kendhang dimainkan dengan cara improvisasi tergantung siapa yang memainkan

Kesenian jamjaneng grup "Sekar Arum" termasuk dalam kategori kesenian yang bertujuan sebagai presentasi estetis dan hiburan pribadi. Kesenian jamjaneng selain bisa dijadikan sebagai media hiburan dalam hal seni, jamjaneng dalam agama islam yaitu bertujuan untuk mendekatkan diri kepada Tuhan dengan doa dan sholawat Nabi yang dilantukan disetiap syair lagunya. Selain itu lagu-lagu yang dinyanyikan ada juga yang menceritakan kesenian jamjaneng itu sendiri.

Pola permainan ritmis dan alat musik yang digunakan masih sangat sederhana, untuk itu peneliti menyarankan untuk menambah variasi pola ritmis agar lebih bervariatif dan menambahkan satu atau dua alat musik melodi agar penikmat seni jamjaneng dan para personil tidak jenuh dengan alat musik yang hanya itu saja. Untuk pemimpin grup "Sekar Arum", intensitas latihan grup lebih baik ditingkatkan seperti mengadakan latihan rutin satu minggu sekali karena fungsi yang ada dalam kesenian jamjaneng sangat positif, misalnya hal ini bisa dilakukan bersama dengan acara membaca surat Yasin rutin setiap malam jumat. 


\section{DAFTAR PUSTAKA}

Alviani, E. (2013). BENTUK PERTUNJUKAN

ORKES DANGDUT PARODI

SENGGOL TROMOL DI

SEMARANG: KAJIAN BENTUK

DAN FUNGSI. Harmonia: Journal Of

Arts Research And Education, 12(1).

Arikunto, Suharsimi. 1983. Prosedur Penelitian :

Suatu Pendekatan Praktik..Jakarta:

Ambarwangi, S., \& Suharto, S. (2013).

PENDIDIKAN MULTIKULTURAL

DI SEKOLAH MELALUI

PENDIDIKAN SENI TRADISI.

Harmonia: Journal Of Arts Research

And Education, 13(1).

doi:http://dx.doi.org/10.15294/harmoni a.v13i1.2535 Bina Aksara.

Susetyo, B. (2011). PERUBAHAN MUSIK REBANA MENJADI KASIDAH MODERN DI SEMARANG SEBAGAI SUATU PROSES DEKULTURASI DALAM MUSIK INDONESIA (THE CHANGE OF REBANA MUSIC TO BECAME MODERN KASIDAH IN SEMARANG A DECULTURATION PROCCES IN INDONESIAN MUSIC). Harmonia: Journal Of Arts Research And Education, 6(2). doi:http://dx.doi.org/10.15294/harmoni a.v6i2.724

Bandem, I Made. 1991. Pengembangan Kesenian Menunjang Pembangunan Daerah. Jakarta: Depdikbud.

Cahyadi, Hasbi Nur. 2015. Fungsi dan Bentuk Penyajian Kesenian Jamjaneng di Dusun Pedurenan Desa Krakal Alian Kebumen.
Djohan. 2003. Psikologi Musik. Yogyakarta: Penerbit Buku Baik.

Hartono. 2000. "Seni Tari dalam Persepsi Masyarakat Jawa" dalam Jurnal Harmonic. Semarang : Sendratasik FBS UNNES

Hendriyanto, Rachmat. 2011. Musik Tradisional Jamjaneng Awak Tugu Manunggal di Desa Kutowinangun Kecamatan Kutowinangun Kabupaten Kebumen : Kajian Pola Permainan Musiknya.

HS, I. (2011). PERKEMBANGAN BENTUK PENYAJIAN DAN FUNGSI EINE KLEINE NACHTMUSIK K.525 KARYA WOLFGANG AMADEUS

MOZART. Harmonia: Journal Of Arts Research And Education, 9(2).

Huberman, A.M. and Miles M.B. 1994. Qualitative Data Analysis: An Expanded Sourcebook. 2nd Edition. Newbury Park: Sage Publication.

Istiyadi, Heru. 2009. Bentuk Penyajian Orkes Keroncong Bakti di Kelurahan Jampiroso Kabupaten Temanggung

Junaidi, Akhmad Arif. 2013. Janengan Sebagai Seni Tradisional Islam-Jawa" membahas Janengan sebagai seni tradisional Islam-Jawa.

Kamus Besar Bahasa Indonesia Pusat Bahasa Edisi Keempat. 2008. Jakarta: PT Gramedia Pustaka Utama.

Kumbini, Marsi. 2009. Bentuk Penyajian Seni Krangkeng Kudasari Desa Asemdoyong Kecamatan Taman Kabupaten Pemalang.

Kurniawan, Benny. 2012. Ilmu Budaya Dasar. Tangerang: Jelajah Nusa.

Maharani, Irma Tri. 2016. Eksistensi Kesenian Kenthongan Grup Titir Budaya di 
Desa Karangduren, Kecamatan Bobotsari, Kabupaten Purbalingga. Di akses melalui Soedarso. 2006. Trilogi Seni : Penciptaan, Eksistensi, dan Kegunaan Seni. Yogyakarta: BP ISI Yogyakarta

Maryono. 2009. Perubahan Bentuk Pertunjukan Seni Karawitan Campursari Kuda Kepang Turonggosari Desa Tambahsari Kecamatan Limbangan Kabupaten Kendal

Merriam, Alan P. 1964. The Anthropology of Music.Northwestern Univerity.

Moeliono, AM. 1983. Kamus Besar Bahasa Indonesia. Jakarta: Balai Pustaka..

Moleong, Lexy. 2000. Metodologi Penelitian Kualitatif. Bandung: PT. Remaja Rosdakarya.

Nakagawa, Shin. 2000. Musik dan Kosmos : Sebuah Pengantar Etnomusikologi. Jakarta: Yayasan Obor Indonesia.

Purwatmo, Rohmad. 2009. Manajemen Sintren Kelompok “Gaya Baru” Desa Dlimas Kecamatan Banyuputih Kabupaten Batang.

Prier, Karl. Edmund. 1996. Ilmu Bentuk Musik.Yogyakarta : Pusat Musik Liturgi.

Saputra, Aditya Budhi. 2016. Kajian Bentuk dan Komposisi Musik Perunjukan Wayang Pring. Fakultas Bahasa dan Seni UNNES.

Sinaga, S. (2011). Fungsi dan Ciri Khas Kesenian Rebana di Pantura Jawa Tengah (Function and Characteristic of Rebana in the Beach Region of Central Java). Harmonia: Journal Of Arts Research And Education, 7(3). ebana). Harmonia: Journal Of Arts Research And Education, 2(3). doi:http://dx.doi.org/10.15294/harmoni a.v2i3.863

Soedarsono. 1999. Seni Pertunjukan dan Pariwisata. Yogyakarta: BP ISI Yogyakarta.

Suharto, S. (2016). Banyumasan Songs As Banyumas People's Character Reflection. Harmonia: Journal Of Arts Research And Education, 16(1), 49-56. doi:http://dx.doi.org/10.15294/harmoni a.v16i1.6460

Taher, Dahlan. 2010. Sejarah Musik 1. Yogyakarta: Jurusan Pendidikan Seni Musik UNY.

Taupik, Nur. 2014. Hubungan Antara Penguasaan Teori Musik Dengan Prestasi Belajar Bermain Ansambel Musik Pada Siswa SMP Negeri 2 Yogyakarta. Di akses melalui eprints.uny.ac.id/19628/1/NurTaupik07 208241017.pdf

Triyanto. 1993. "Pendidikan Seni Sebagai Proses Enkulturasi Nilai - nilainya Budaya" dalam Media FPBS. Semarang : IKIP Semarang Press.

Utari, Maria Tri. 2011. Eksistensi Pembelajaran Tari Jawa Pada Siswa Etnis Tionghoa di SMP Karangturi Semarang. 